\title{
ACUTE PANCREATITIS AND ACUTE RENAL FAILURE FOLLOWING MULTIPLE HORNET STINGS
}

\section{SHARMA N. (1), BALAMURUGESHAN P. K. (1), SHARMA A. (1)}

(1) Department of Internal Medicine, Postgraduate Institute of Medical Education and Research, Chandigarh, India.

ABSTRACT: Hymenoptera is a class of insects that sting in order to subdue their prey. Humans coming into accidental contact with these insects results in stings that may cause from mild local reaction like weal formation around the sting site to severe systemic reactions such as intravascular hemolysis, acute renal failure, pulmonary edema, cerebral edema, and rarely pancreatitis. We report here the clinical course of a patient who developed concurrent acute pancreatitis and pigment-induced acute renal failure after multiple hornet stings.

KEY WORDS: Hymenoptera, acute renal failure, rhabdomyolysis, hemolysis, pancreatitis, hornet stings.

\section{CORRESPONDENCE TO:}

NAVNEET SHARMA, Postgraduate Institute of Medical Education and Research, 160012, Chandigarh, India. Phone: 00910172 2747585. Ext.: 3653. Fax: 00910172 2744401. Email: navneet 433@sify.com or navneet207@yahoo.com.in. 


\section{INTRODUCTION}

Insects that sting to subdue their prey belong to the class Hymenoptera. Prominent amongst this class are the vespids, which include wasps, hornets, and yellow jackets $(5,7)$. The venom of these species contains a wide assortment of peptides, amines, and enzymes that are responsible for the local and systemic effects of the venom. Stings are seldom fatal and usually lead to profound local inflammatory reaction. However, multiple hornet stings can cause hypotension, anaphylaxis, dyspnea, collapse, rhabdomyolysis, and acute renal failure $(1,3,5,7,8)$. We report here a case of multiple hornet stings that led to pigment-induced acute renal failure and pancreatitis. To the best of our knowledge, such a presentation of hornet sting envenomation with both acute renal failure and pancreatitis has never been reported before.

\section{CASE DESCRIPTION}

A 60-year old man presented to the Emergency Medical Services of the Postgraduate Institute of Medical Education and Research, Chandigarh, India, with a history of multiple hornet stings while cutting trees in a rural area. Following the stings, he complained of dizziness, generalized body aches, abdominal pain that radiated to the back, and vomited many times. Over the next 48 hours, the abdomen became distended and obstipation set in. He reported to a primary health care center, where first aid was administered in the form of adrenaline and hydrocortisone. Four days after the hornet stings, a change in the color of urine to cola was observed and the urine output decreased progressively. He was then referred to our hospital for further management.

On evaluation at our hospital, the general physical examination was unremarkable. On a review of the systems, the heart and lungs were normal, and examination of the abdomen showed an abdominal distension with rigidity in the epigastric area. On auscultation, bowel sounds were absent. Laboratory investigations revealed blood hemoglobin level of 6 grams per deciliters and normal complete blood leucocytes count. Biochemical tests showed elevated blood urea $(213 \mathrm{mg} \%$ ) and serum creatinine of $6.2 \mathrm{mg} \%$. The arterial blood gas analysis suggested a compensated metabolic acidosis. On evaluation for pigment-induced nephropathy, the creatinine phosphokinase-MM isoenzyme level was 5857U/I (normal = 24-195U/I), plasma 
hemoglobin was $114 \mathrm{mg} / \mathrm{dl}$, and urinary hemoglobin was $67 \mathrm{mg} / \mathrm{dl}$. The levels of red blood cell glucose-6-phosphatase dehydrogenase enzyme were normal. Investigations for pain in the abdomen showed that the serum amylase was 400 Somogyi units [SU] (normal $<200 \mathrm{SU}$ ) and the ascitic fluid amylase level was 1600 SU. The X-ray of the abdomen disclosed multiple dilated bowel loops and ultrasound of the abdomen showed a normal biliary system. A contrast-enhanced computerized tomographic scanning of the abdomen showed acute pancreatitis (Grade C) with intrapancreatic collection in the tail region (Figure 1) and dilated bowel loops.

He was admitted with a diagnosis of pigment-induced acute renal failure and acute pancreatitis. Serial sessions of hemodialysis were carried out, during which packed red cells were also transfused to raise hematocrit to $30 \%$. Therapy for acute pancreatitis consisted of 'nil per oral' regimen and intravenous fluids. Over the next 3 days, bowel sounds returned and pain in the abdomen subsided. Seven days after admission and after five sessions of hemodialysis, the urine output improved and the renal failure resolved. He was discharged 12 days after admission in a satisfactory condition.

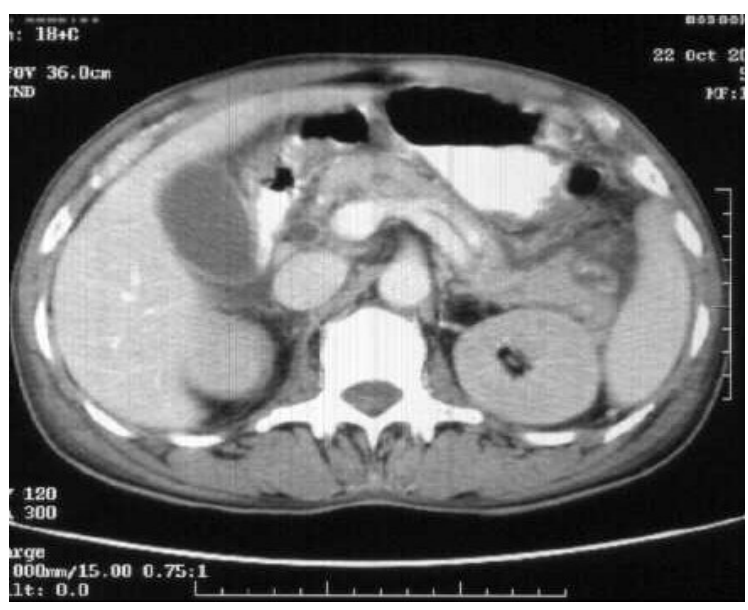

Figure 1: Computerized tomographic scanned images of the abdomen showing dilated bowel loops, a bulky pancreas, loss of peri-pancreatic fat planes and stranding in the tail region.

\section{DISCUSSION}

The venoms of different species of Hymenoptera are biochemically and immunologically distinct. The honey bees (Apis mellifera) venom contains many low molecular weight compounds such as serotonin, histamine, acetylcholine, several 
kinins; two enzymes (phospolipase $A_{2}$, hyaluronidase); polypeptides like melittin (hemolysin) and apamin (neurotoxin); and a mast cell degranulating protein (5). Stings by Hymenoptera species cause from a mild local reaction like weal formation around the sites with surrounding erythema to severe systemic reactions like intravascular hemolysis, acute renal failure, pulmonary edema, cerebral edema, and pancreatitis (1-5, 7-8).

Acute renal failure following multiple hornet stings is a well-established entity $(1,3,5$, 7 , 8). The underlying mechanism is of an intravascular hemolysis and/or rhabdomyolysis causing pigment nephropathy and acute tubular necrosis $(1,3,8)$. The venom of yellow jackets contains many toxic substances like phospholipases, hyaluronidases, and a toxic protein known as antigen 5 (8). These toxins can damage red blood cells and myocyte membranes causing hemolysis and rhabdomyolysis $(1,3,8)$. The resultant excess of both hemoglobin and myoglobin pigments leads to acute tubular necrosis and renal failure. A direct toxic effect of the venom on renal tubular cells has also been proposed (1). Our patient had both intravascular hemolysis and elevated serum creatinine phosphokinase-MM isoenzyme levels suggesting rhabdomyolysis.

Acute pancreatitis following multiple hornet stings is a rarely reported phenomenon. In literature, we could come across only a report of two cases of acute pancreatitis demonstrated at autopsy following multiple Africanized bee stings (4). Phospolipase A2 (PLA2) is an active component of bee and snake venoms as well as of the mammalian pancreatic juice. This compound is believed to play an important role in causing acute pancreatitis (2). A large amount of PLA2 is released during human acute pancreatitis and is implicated in the pathology of pancreatic necrosis and pancreatitis-associated pulmonary failure. On the contrary, an in vitro study has shown that PLA2 from bee venom (Apis mellifera) had no effect on MCF-7 breast cancer cells culture (6). The authors of this study thus concluded that the toxicity of bee PLA2 in vivo may also depends on the presence of other substances.

The other substance present in Hymenoptera venom that has been implicated in cell toxicity is melittin. This compound, melittin, has low molecular weight, is highly basic and able to insert itself into the phospholipid bilayer of cell membranes and, in conjunction with PLA2, it causes membrane disruption including lyses of red blood 
cells, leucocytes, platelets, and vascular endothelium (4). Melittin may thus act in conjunction with PLA2, on pancreatic acinar cells to induce acute pancreatitis.

In conclusion, multiple hornet stings led to hemolysis, rhabdomyolysis-induced acute renal failure and pancreatitis in our patient. Thus, patients presenting multiple hornet stings with abdominal pain should be investigated for pancreatitis.

\section{REFERENCES}

1 BOUSQUET J., HUCHARD G., MICHEL FB. Toxic reactions induced by Hymenoptera venom. Ann. Allergy, 1984, 52, 371-4.

2 BUCHLER M., MALFERTHEINER P., SCHADLICH H., NEVALAINEN TJ., FRIESS H., BEGER HG. Role of phospholipase A2 in human acute pancreatitis. Gastroenterology, 1989, 97, 1521-6.

$3 \mathrm{CHUGH}$ KS., SHARMA BK., SINGHAL PC. Acute renal failure following hornet stings. J. Trop. Med. Hyg., 1976, 79, $42-4$.

4 DAISLEY $H$. Acute haemorrhagic pancreatitis following multiple stings by Africanized bees in Trinidad. Trans. R. Soc. Trop. Med. Hyg., 1998, 92, 71-2.

5 ELLENHORN MJ., BARCELOUX DG. Envenomations from bites and stings. In: ELLENHORN MJ., BARCELOUX DG. Eds. Medical Toxicology. Diagnosis and treatment of human poisoning. New York: Elsevier, 1988: 1133-41.

6 MARTIKAINEN P., NYMAN K., NEVALAINEN TJ. Toxic effects of human pancreatic and snake and bee venom phospholipases A2 on MCF-cells in culture. Toxicon, 1993, 31, 835-43.

7 REISMAN RE. Insect stings. N. Engl. J. Med., 1994, 331, 523-7.

8 SUBRAMANIAN C., JAIN V., SINGH M., KUMAR L. Allergic and systemic reactions following yellow jacket stings. Indian Pediatr., 2000, 37, 1003-5. 